\title{
THE AMMA LAND SURFACE MODEL INTERCOMPARISON PROJECT (ALMIP)
}

\author{
by Aaron Boone, Patricia de Rosnay, Gianpaolo Balsamo, Anton Beljaars, Franck Chopin, \\ Bertrand Decharme, Christine Delire, Agnes Ducharne, Simon Gascoin, Manuela Grippa, \\ Françoise Guichard, Yeugeniy Gusev, Phil Harris, Lionel Jarlan, Laurent Kergoat, \\ Eric Mougin, Olga Nasonova, Anette Norgaard, Tristan Orgeval, Catherine Ottlé, \\ Isabelle Poccard-Leclerce, Jan Polcher, Inge Sandholt, Stephane Saux-Picart, \\ Christopher Taylor, and Yongkang Xue
}

\section{A multimodel comparison of the performance of land surface parameterization schemes increases understanding of the land-atmosphere feedback mechanisms over West Africa.}

$\mathrm{T}$ he West African monsoon (WAM) circulation modulates the seasonal northward displacement of the intertropical convergence zone (ITCZ). It is the main source of precipitation over a large part of West Africa. However, predominantly relatively wet years during the 1950s and 1960s were followed by a much drier period during the 1970s and 1990s. This extreme rainfall variability corresponds to one of the strongest interdecadal signals on the planet over the last halfcentury. There is an urgent need to better understand and predict the WAM, because social stability in this region depends to a large degree on water resources. The economies are primarily agrarian, and there are issues related to food security and health. In addition, there is increasing pressure on the already limited water resources in this region, owing to one of the most rapidly increasing populations on the planet.

Numerous researchers over the last three decades have investigated the nature of the extreme rainfall variability (e.g., Nicholson 1980; Le Barbé et al. 2002). It has been shown that a significant part of the interannual variability can be linked to sea surface (sfc) temperature anomalies (e.g., Folland et al. 1986; Fontaine and Janicot 1996), but there is also evidence that land surface conditions over West Africa make a significant contribution to this variability (e.g., Nicholson 2000; Philippon et al. 2005).

Importance of the land-atmosphere interactions on the WAM. The monsoon flow is driven by land-sea thermal contrast. The atmosphere-land surface interactions are modulated by the magnitude of the associated north-south gradient of heat and moisture in the lower atmosphere (Eltahir and Gong 1996). The links between land surface processes and the WAM have been demonstrated in numerous numerical studies using global climate models (GCMs) and regional-scale atmospheric climate models (RCMs) over the last several decades. Charney (1975) were one of the first set of researchers to use a coupled land surface-atmosphere model to demonstrate a proposed positive feedback mechanism between decreasing vegetation cover and the increase in drought conditions across the Sahel region of western Africa. Numerous modeling studies since have examined the influence of the land surface on the WAM in terms of surface albedo (e.g., Sud and Fennessy 1982; Laval and Picon 1986), the vegetation spatial distribution (e.g., 
Xue and Shukla 1996; Xue et al. 2004; Li et al. 2007), and the soil moisture (e.g., Walker and Rowntree 1977; Cunnington and Rowntree 1986; Douville et al. 2001). However, interpretation of the results, from any one of such studies, must be tempered by the fact that there are substantial discrepancies in African land-atmosphere coupling strength among current state-of-the-art GCMs (Koster et al. 2002).

There is also a need to study and provide estimates of changes in rainfall variability resulting from predicted global climate change. Indeed, studies using GCMs have indicated that the impact in this region could be further amplified, owing to surface anthropogenic factors such as clearing the land of natural vegetation for crops and overgrazing (e.g., Xue et al. 2004). The above-mentioned factors will not only affect the atmosphere but also the regional-scale hydrology in terms of changes in runoff regimes. This, in turn, would impact the quantity of water stored in surface reservoirs and the recharge of local and regional water tables. However, it should be noted that considerable progress is needed in order to develop reliable estimations of land-atmosphere impacts for GCM climate scenarios. A recent study examining the performance of GCMs within the Intergovernmental Panel on Climate Change (IPCC) framework showed that models have significant problems simulating key aspects of the WAM for the present climate. Even the GCMs that show some skill produce considerably different West African climatologies at the end of this century (Cook and Vizey 2006).

Improving models in order to better understand and predict the WAM. The deficiencies, with respect to modeling the African monsoon, arise from both the paucity of observations at sufficient space-time resolutions, and because of the complex interactions of the relevant processes between the biosphere, atmo-

AFFILIATIONS: BOONE, DECHARME, AND GUICHARD-GAME-Centre National de Recherche Météorologique, Toulouse, France; De Rosnay, Balsamo, and BeljaARS - European Centre for Medium-Range Weather Forecasts, Reading, United Kingdom; CHOPIN, ORGEVAL, AND POLCHER - IPSL, Laboratoire de Météorologie Dynamique, Paris, France; DeLIRE-ISE-Montpellier, Université Montpellier 2, Montpellier, France; DuCHARNE AND GASCOIN-Sisyphe, Université Pierre et Marie Curie (UMPC/CNRS), Paris, France; GrIPPA, Jarlan, Kergoat, and Mougin - Centres d'Etudes Spatiales de la Biosphère, Toulouse, France; GuSEV AND NASONOVA-Institute of Water Problems, Russian Academy of Sciences, Moscow, Russia; HARRIS AND TAYLOR-Centre for Ecology and Hydrology, Wallingford, United Kingdom; NORGAARD AND SANDHOLT-Institute of Geography, University of Copenhagen, Copenhagen, Denmark; OTTLÉ-IPSL- sphere, and hydrosphere over this region. The African Monsoon Multidisciplinary Analysis (AMMA) has organized comprehensive activities in data collection and modeling to further increase our understanding of the relevant processes, in order to improve prediction of the WAM (Redelsperger et al. 2006). In terms of large-scale atmospheric multimodel initiatives, the AMMA Model Intercomparison Project (MIP; Hourdin et al. 2010) intercompares GCMs and RCMs over a meridional transect in West Africa, focusing on seasonal prediction. The West African Monsoon Modeling and Evaluation (WAMME) project utilizes such models to address issues regarding the role of ocean-land-aerosol-atmosphere interactions on WAM development (Xue et al. 2009, manuscript submitted to Climate Dyn.). The modeling of the land surface component of the WAM is being addressed by the AMMA Land Surface Model (LSM) Intercomparison Project (ALMIP), which is the focus of this paper.

Land surface modeling initiatives. In recent years, there have been a number of LSM intercomparison projects on an international level. In particular, the Project for the Intercomparison of Land-Surface Parameterization Schemes (PILPS) has increased the understanding of LSMs, and it has lead to many model improvements. In phase 2 of PILPS (Henderson-Sellers et al. 1995), LSMs were used in so-called offline mode (i.e., the LSM is uncoupled from an atmospheric model and is therefore driven using prescribed atmospheric forcing either from observations, satellite products, atmospheric model data, or some combination of those three sources), and the resulting simulations were compared to observational data. The first attempt by PILPS to address LSM behavior at a regional scale was undertaken in PILPS-2c (Wood et al. 1998). The Global
Laboratoire des Sciences du Climat et de l'Environnement, Gif-surYvette, France; PoCCARD-LECLERCQ-LETG-Géolittomer, Université de Nantes, Nantes, France; SAUX-PICART-IFREMER, Laboratoire d'Océanographie Spatiale, Plouzané, France; XUE-University of California, Los Angeles, Los Angeles, California CORRESPONDING AUTHOR: Aaron Boone, GAME-CNRM Météo-France, 42 ave G. Coriolis, Toulouse, France 31057 E-mail: aaron.boone@meteo.fr

The abstract for this article can be found in this issue, following the table of contents.

DOI:10.1175/2009BAMS2786.1

In final form 15 June 2009

(C) 2009 American Meteorological Society 
Soil Wetness Project, Phase 2 (GSWP-2; Dirmeyer et al. 2006a) was an offline global-scale LSM intercomparison study that produced the equivalent of a land surface reanalysis consisting in 10-yr global datasets of soil moisture, surface fluxes, and related hydrological quantites. The Rhône aggregation LSM intercomparison project (Boone et al. 2004) differed from the above-mentioned studies because the impact of changing the spatial scale on the LSM simulations was investigated. The main idea behind ALMIP is to take advantage of the significant international effort of the intensive field campaign and the various modeling efforts in order to better understand the role of land surface processes in the WAM.

ALMIP SCIENTIFIC OBJECTIVES. The strategy proposed in AMMA is to break the various components of the fully coupled system into more manageable portions. The first step is to begin with the LSM in offline mode. The multimodel offline technique has been used by numerous intercomparison projects (see appendix B). It is also used in operational land data assimilation systems (LDASs), such as the North American LDAS (NLDAS; Mitchell et al. 2004) and the Global LDAS (GLDAS; Rodell et al. 2004) for potential operational NWP applications. In addition, Douville et al. (2001) assimilated offline soil moisture into a GCM, as a proxy for reality, to study WAM surface-atmosphere feedback mechanisms.

Offline results have also been used for improved atmospheric model initialization. For example, ALMIP results are currently being used for numerous mesoscale case studies within AMMA [such as a study of feedbacks between dust emissions and the atmosphere in Tulet et al. (2008)], and to examine the influence of initial soil moisture on NWP at the European Centre for Medium-Range Weather Forecasts (ECMWF; A. Agusti-Panareda 2009, personal communication). In addition, ALMIP results have also been recently used for evaluating the land surface component of GCM and RCM (e.g., Steiner et al. 2009; Hourdin et al. 2010; Boone et al. 2009; Xue et al. 2009, manuscript submitted to Climate Dyn.).

The idea is to force state-of-the-art land surface models with the best quality and highest (space and time) resolution data available to better understand the key processes and their corresponding scales. The ALMIP therefore has the following main objectives:

1) intercompare results from an ensemble of stateof-the-art models and study model sensitivity to different parameterizations and forcing inputs;
2) determine which processes are missing, or are not adequately modeled, by the current generation of LSMs over this region;

3) examine how the various LSM respond to changing the spatial scale (three scales will be analyzed: local, mesoscale, and regional);

4) Develop a multimodel climatology of "realistic" high-resolution (multiscale) soil moisture, surface fluxes, and water and energy budget diagnostics at the surface (which can then be used for coupled land-atmosphere model evaluation, case studies, etc.); and

5) evaluate how relatively simple LSMs simulate the vegetation response to the atmospheric forcing on seasonal and interannual time scales.

ALMIP is an ongoing project, and phase 1 (regional-scale studies), which addresses items 1 and 4, has recently been completed; highlights from these items will be presented in this paper. In terms of item 1, the LSMs have run three multiyear experiments to explore LSM sensitivity to different input meteorological forcings. We present a brief overview of intercomparison results, along with some examples of evaluation efforts, which are under way (item 4). The next phase of ALMIP (phase 2) will begin this year, and it will address the remaining items (2, 3, and 5) by focusing on the meso- and local scales. We will also give general conclusions from phase 1 and perspectives for the next phase of ALMIP.

\section{LAND SURFACE MODEL FORCING AND EXPERIMENTS. The creation of a multiscale} low-level atmospheric forcing database over land is essential for a coherent multidisciplinary study with diverse LSMs. The forcing database is composed of land surface parameters, atmospheric state variables, precipitation, and downwelling radiative fluxes. The database has three scales (regional, mesoscale, and local), but we only used the regional-scale data for ALMIP phase 1 described here. All of the models use the same computational grid at a $0.50^{\circ}$ spatial resolution (see domain in Fig. 1). The same soil-vegetation database is used for all experiments (see appendix A). Three experiments explored the LSM sensitivity to different input meteorological forcings (notably precipitation, which is the most critical field).

Control atmospheric forcing. The atmospheric forcing is based on the ECMWF NWP model forecasts for the years 2002-07. The forcing variables consist in the air temperature, specific humidity, and wind components at $10 \mathrm{~m}$, the surface pressure, the total and 


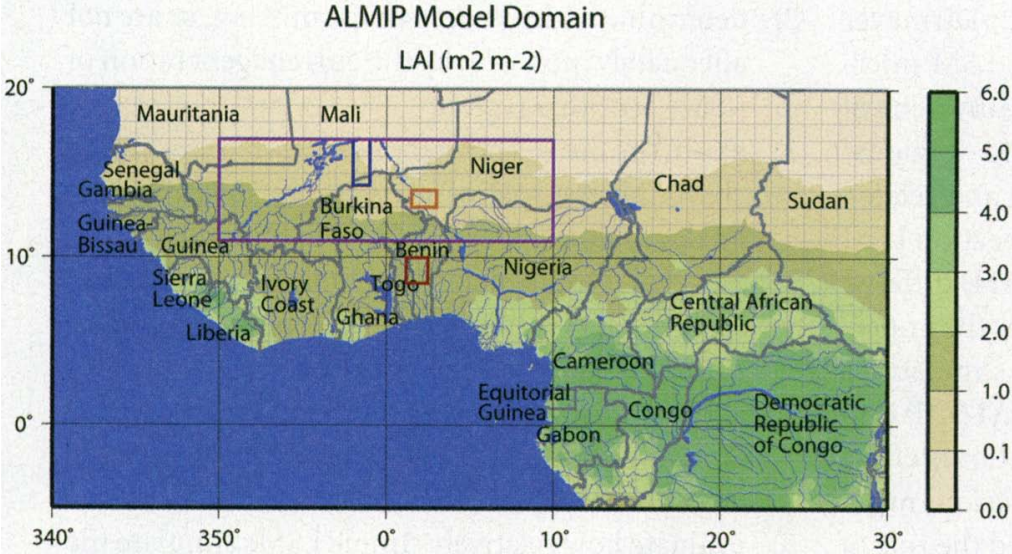

FIG. I. The ALMIP regional-scale (phase I) model domain. The three mesoscale supersites are indicated by boxes: Mali (blue), Niger (orange), and Benin (red). The Sahel box (referred to herein) is represented also (violet). The color shading corresponds to the annual average leaf area index $\left(\mathrm{LAI} ; \mathrm{m}^{2} \mathrm{~m}^{-2}\right.$ ) from the Ecoclimap database.

Most of the precipitation events are convective, and thus relatively short lived for a given point. The Estimation des Pluies par Satellite Seconde Géneration (EPSAT-SG; Chopin et al. 2004) precipitation product from the AMMA satellite componet (AMMA-SAT; online at ammasat.ipsl. polytechnique.fr) offers the appropriate resolution and was developed especially to merge satellite and ground observations. This rainfall data were used for experiment 2 .

The research community has increasingly demanded a longer-term record of surface fluxes and soil moisture. However, the experiment 2 precipitation data are only available during the core monsoon period

convective rain rates, and the downwelling longwave and shortwave radiative fluxes (see appendix A for more details). There are, of course, several operational global-scale NWP models to choose from for forcing data. When ALMIP began (in 2003), ECMWF data were selected because the forecast data were available at approximately $50-\mathrm{km}$ spatial resolution over West Africa, and this model simulated the regional-scale circulation over West Africa (e.g., Nuret et al. 2007) relatively well. These data comprise the experiment 1 or control forcing.

Merged atmospheric forcing. Because of the scarcity of surface observations over most of western Africa, remotely sensed data are needed for creating largescale LSM forcing. The corresponding algorithms are generally calibrated, or supplemented, by any available local-scale data. Satellite-based data are most commonly available for the downwelling solar and atmospheric radiative fluxes and the rainfall. The radiative fluxes from the Ocean and Sea Ice Satellite Application Facility (OSI SAF; online at www.osi-saf.org) for 2004 and the Land Surface Analysis Satellite Application Facility (LSA SAF; Geiger et al. 2008) fluxes for 2005-07 are substituted for the corresponding NWP fluxes in experiments 2 and 3. They have been evaluated over this region (and this work is ongoing as more observational data become available).

Rainfall is the most problematic variable produced by NWP models, especially over West Africa. In ALMIP, however, we are limited to rainfall products with maximum time steps on the order of a few hours, because the LSMs in ALMIP resolve the diurnal cycle.
(May-June) from 2004 to 2006. For this reason, we ran an additional experiment (experiment 3 ) with the Tropical Rainfall Measuring Mission (TRMM) precipitation product 3B-42 (Huffman et al. 2007) from 2002 to 2007 (hereafter this product is referred to as TRMM in this paper). The TRMM rainfall estimates combine calibrated microwave and infrared precipitation estimates, rescaled to monthly gauge data, and have a 3-h time step. Nicholson et al. (2003) showed that TRMM-combined products performed well on a monthly time scale over West Africa compared to other available products.

The ECMWF model captures most of the main dynamical features of the WAM, but the simulated monsoon precipitation does not extend far enough to the north (Fig. 2a). Clearly, experiment 2 precipitation shows a northward displacement of the monsoon characterized by both increased precipitation to the north (roughly north of $8^{\circ} \mathrm{N}$ ) and decreased values along the southern coast. In particular, the experiment 2 rainfall is approximately $9 \%$ higher over the Sahel region (indicated in Fig. 1) where the experiment 12006 June-September (JJAS) average rainfall is $3.8 \mathrm{~kg} \mathrm{~m}^{-2}$ day $^{-1}$, with the largest local relative increases over the northern part of this region. Further evidence of this problem will be given in the "Simulation evaluation methodology" section using satellite-based information. Downwelling shortwave radiation shows the same difference (Fig. $2 b$ ). The experiment 2 values are generally lower where pre-

\footnotetext{
${ }^{1}$ Note that the TRMM product has evolved since the abovementioned study, but studies within AMMA have more recently come to the same conclusion.
} 
cipitation and clouds have increased (the difference correspondes to about a 1\% Sahel-average decrease for JJAS in experiment 2, although local decreases approach approximately $10 \%)$. This comparison emphasizes the importance of ancillary information to derive LSM forcings to reduce NWP model defaults or biases. The ultimate goal of ALMIP is to obtain more realistic estimates of surface processes.

\section{SIMULATED SURFACE PROCESSES.}

Previous intercomparison studies have highlighted the necessity to use an ensemble of LSMs. Each individual model has its own biases and errors. Eleven LSMs participated in ALMIP phase 1 (see Table 2 and appendix B). Nine of the models used the provided Ecoclimap database soil and monthly varying vegetation parameter information; two LSMs used their native set of parameters. This implies that most of the model differences should be related to physics as opposed to parameters. of using the satellite-merged forcing is quite significant. Evap increases over $1 \mathrm{~kg} \mathrm{~m}^{-2}$ day $^{-1}$ (with local increases of well over $2 \mathrm{~kg} \mathrm{~m}^{-2}$ day $^{-1}$ ) covering a large region north of approximately $8^{\circ} \mathrm{N}$, with decreases along the southern West African coast. This response is consistent with the experiments 2 and 1 precipitation and radiation forcing differences shown in Fig. 2.

Even though different satellite-based precipitation products are merged with observational data, they can still have significant differences. Therefore, we compared ALMIP results for the three different forcing datasets. For each LSM and year from 2004 to 2006 in Fig. 4, the JJAS runoff ratio (the ratio of the total runoff to the rainfall) for the Sahel is plotted as a function of the latent heat ratio (here defined as the ratio of the latent to the net radiative flux). A low runoff ratio implies that much of the rainfall is going into evaporation or soil water storage (and therefore little is left for river flow). The latent heat ratio gives an estimate of the fraction of
Intercomparison overview. One of the most critical land surface fields is evapotranspiration (Evap). This flux forms the critical link between land surface hydrology and the atmosphere. Despite the fact that the LSMs are using the same input atmospheric forcing, they show differences in the Evap spatial distribution in experiment 2 (Fig. 3). Of particular importance for the WAM are intermodel differences over the Sahel (essentially north of approximately $10^{\circ} \mathrm{N}$ ). The meridional gradient of Evap is a maximum in this region during the monsoon season. When averaged over $-10^{\circ}$ to $10^{\circ} \mathrm{E}$ longitude, the gradient varies among the LSMs by up to approximately a factor of 2 (with the LSMs fairly equally distributed within this range). Because this gradient is coupled with the WAM circulation and intensity (Eltahir and Gong 1996), the strength of the feedbacks in different fully coupled land-atmosphere models could vary considerably, because of surface Evap parameterization differences (Dirmeyer et al. 2006b).

The difference between the multimodel average Evap in experiments 2 and 1 (Fig. 3p) shows that the impact
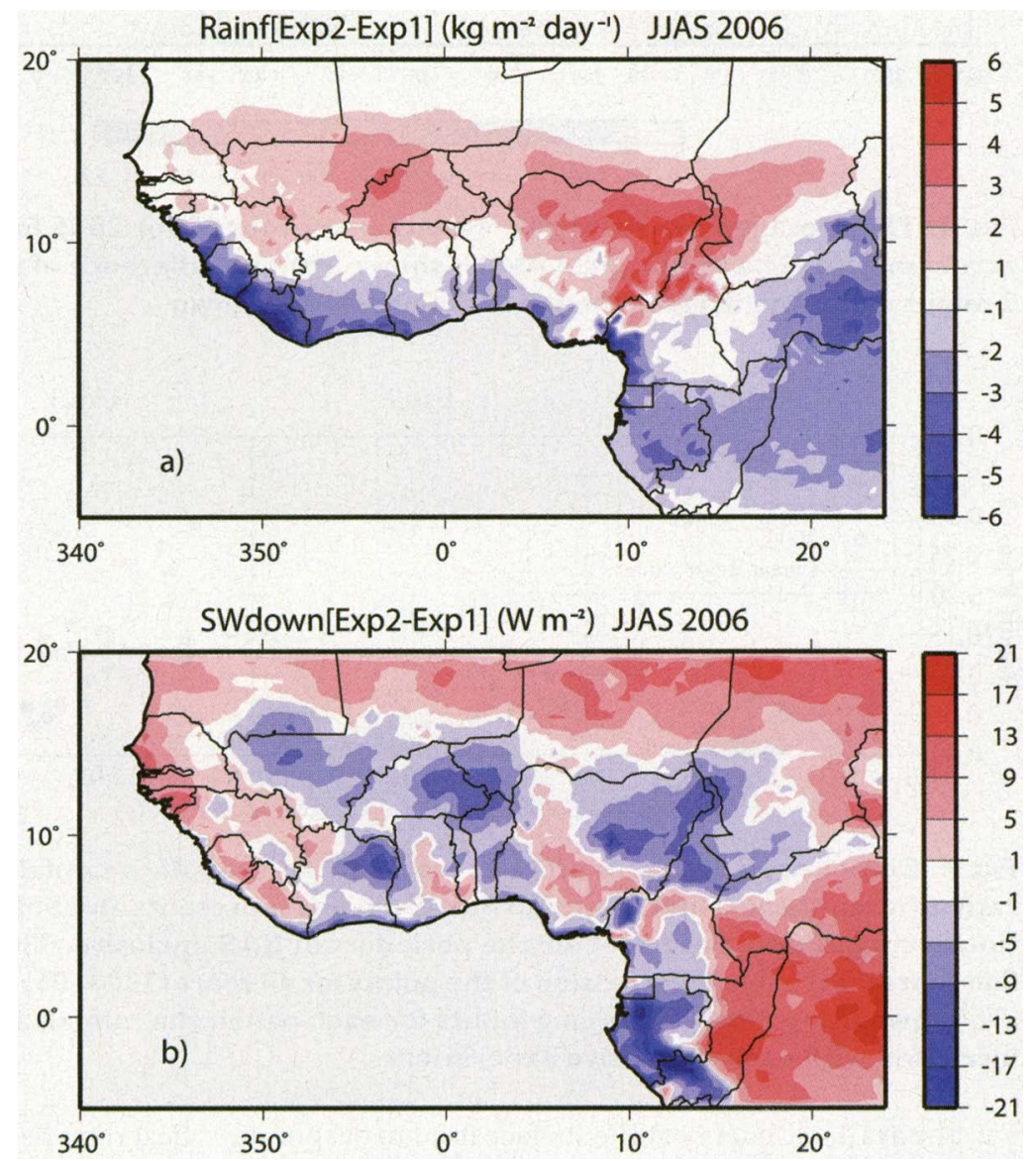

FIG. 2. (a) The JJAS average rainfall rate (Rainf) for 2006 from experiment 2 (EPSAT ECMWF forcing) less that from experiment I (pure ECMWF forcing) is shown. (b) The corresponding difference for the downwelling shortwave radiation (SWdown) is shown also, for which experiment 2 forcing consists in LSA SAF ECMWF data. 

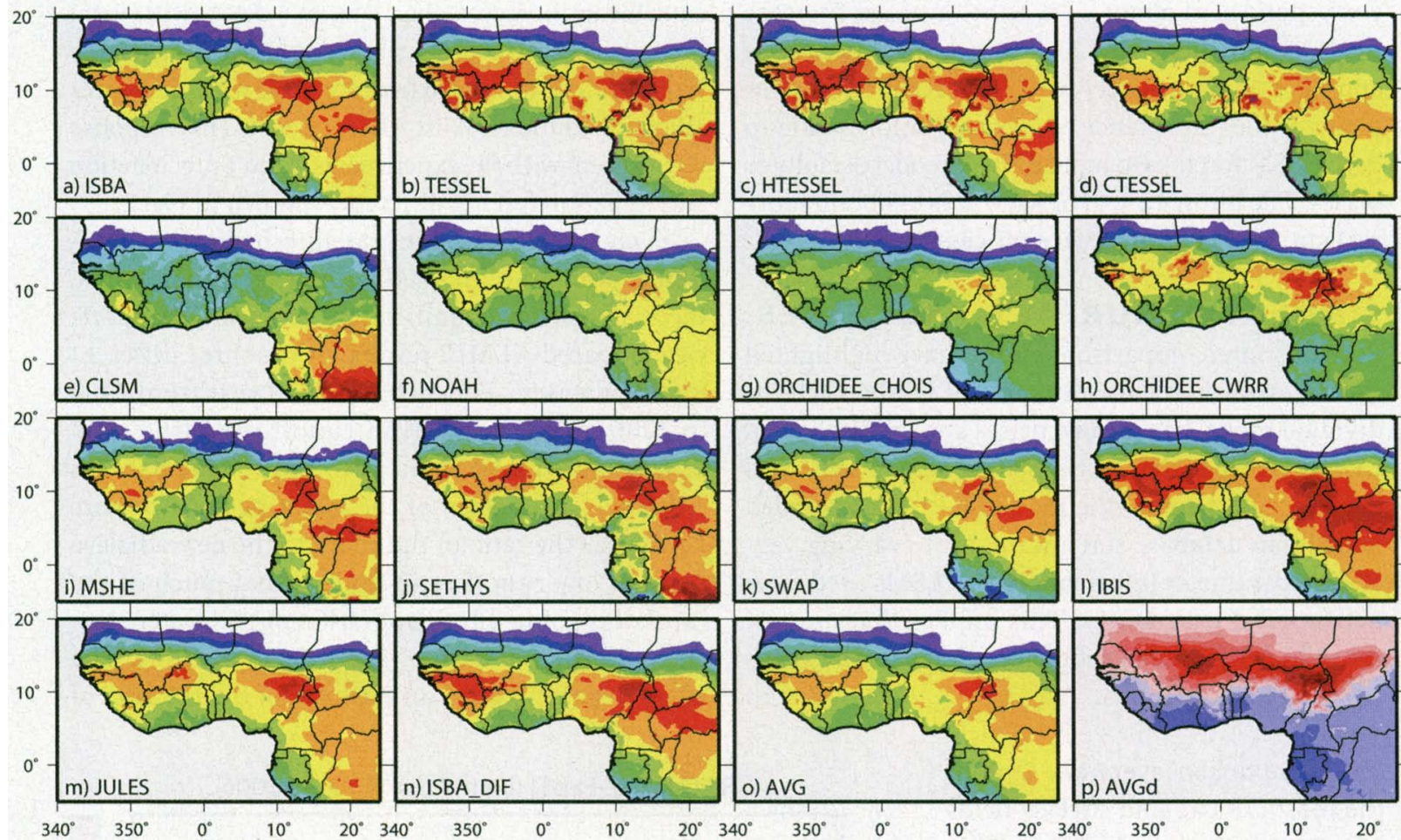

$\begin{array}{lllllllllllllll}0.0 & 0.4 & 0.8 & 1.2 & 1.6 & 2.0 & 2.4 & 2.8 & 3.2 & 3.6 & 4.0 & 4.4 & 4.8 & 5.2\end{array}$

$\begin{array}{lllllllllllll}-1.6 & -1.2 & -0.8 & -0.4 & 0.0 & 0.4 & 0.8 & 1.2 & 1.6 & 2.0 & 2.4 & 2.8\end{array}$

FIG. 3. The average Evap ( $\mathrm{mm}$ day $^{-1}$ ) from experiment 2 for 2006 for 14 LSMs (see Table 2 for a list of model acronyms). (o) The multimodel AVG is shown. (p) The difference of the multimodel average Evap (experiment 2 minus experiment $I$ ) for the same time period is shown.

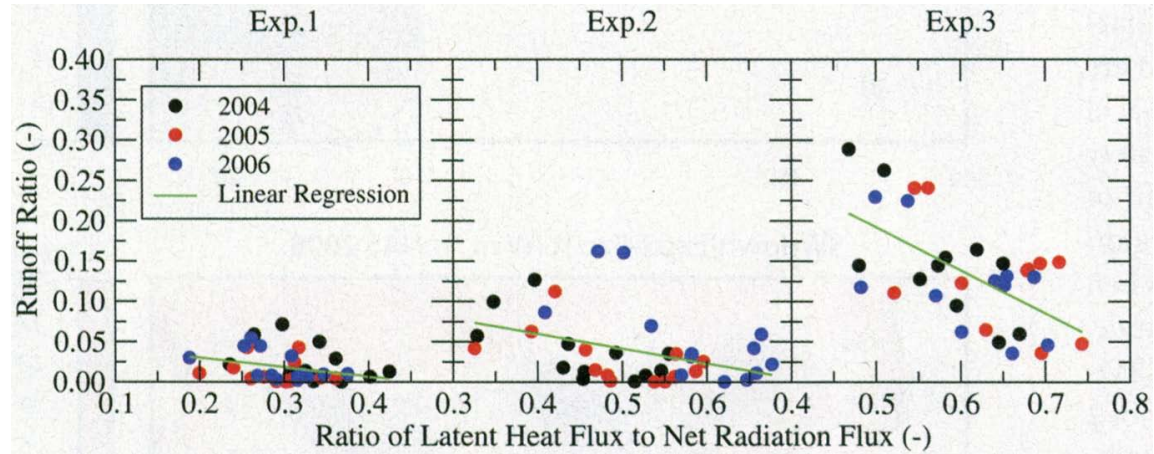

FIG. 4. Comparison of the runoff ratio (ratio of total runoff to rainfall) to the ratio of latent heat to net radiation flux. Each dot represents an LSM simulation averaged over the Sahel for the period from JJAS, inclusive. The green line represents a linear regression of the points for all years (2004-06). Results are shown using different forcing inputs for each panel: the rainfall amounts increased with each successive experiment.

the available energy at the surface used to evaporate water. The remaining fraction goes into heating the atmosphere.

It can be seen from Fig. 4 that the NWP forcing rainfall (experiment 1) results in an LSM average runoff ratio of 0.012 . Nearly all of the rainfall is evaporated, but this still leaves most of the surface energy for sensible heating of the atmosphere (the LSM average latent heat ratio is 0.31 ). There is essentially no statistical relationship between the two ratios. There is $60 \%$ less rainfall and $50 \%$ less evaporation in experiment 1 than in experiment 2 over the Sahel (see Fig. 2). The larger experiment 2 rainfall increases both the runoff and latent heat ratios (the average latent heat ratio has increased to 0.51 in Fig. 4). The experiment 3 rainfall (TRMM) is even larger, resulting in $25 \%$ more rainfall and $18 \%$ more evaporation than that in experiment 2 . There are much larger runoff ratios, and there is a greater statistical relationship between the latent heat and runoff ratios (the cor- 
relation is -0.61 ); for the same input rainfall, increased runoff results in lower evaporation. In terms of physical processes, the models with the least surface runoff in experiments 2 and 3 tend to have the largest latent heat ratios, but for the remaining models there is no obvious relationship. In experiment 3 , the rainfall exceeds the evaporative demand in many of the models, at times, resulting in considerably more runoff (therefore more water is available for river flow). The LSM simulation of river flow is currently being investigated, and it will be addressed in more detail in ALMIP phase 2. Finally, in the Sahel, the average interexperiment differences are far larger than the average of the intermodel differences for each experiment. This highlights the need to use satellite-based forcing data, whenever possible, to correct NWP model systematic biases.

Characterization of the water and energy budgets by the LSM ensemble. Gao and Dirmeyer (2006) showed the advantages and improved realism of using a multi-LSM model average to study simulated surface properties. They presented several different weighting techniques from the simple average to one using optimized weights that minimized errors based on observations. The low spa-

tial density of surface observations over West Africa precluded such optimization techniques, so we used the simple ensemble mean of the ALMIP-simulated surface fluxes (see appendix B for further details).

Figure 5 presents a summary of the water and energy budgets simulated by the LSMs and the ensemble LSM
TABLE I. Summary of ALMIP phase I forcing inputs for each of three experiments. Here NWP data refer to those from the ECMWF forecast model. SAF refers to data from the OSI SAF (for 2004) and the LSA SAF (2005-07). EPSAT and TRMM 3 B42 correspond to precipitation products consisting of merging satellite-based and rain-gauge estimates. See text for more details.

\begin{tabular}{|c|c|c|c|}
\hline $\begin{array}{c}\text { Experiment: } \\
\text { Time period }\end{array}$ & $\begin{array}{c}\text { Meteorological } \\
\text { state variable } \\
\text { source }\end{array}$ & $\begin{array}{c}\text { Incoming } \\
\text { radiative flux } \\
\text { source }\end{array}$ & $\begin{array}{c}\text { Precipitation } \\
\text { source }\end{array}$ \\
\hline I: $2002-06$ & NWP & NWP & NWP \\
\hline 2: $2004-06$ & NWP & $\begin{array}{c}\text { Merged NWP } \\
\text { and SAF }\end{array}$ & $\begin{array}{c}\text { Merged NWP } \\
\text { and EPSAT }\end{array}$ \\
\hline 3: $2002-07$ & NWP & SAF & TRMM 3B42 \\
\hline
\end{tabular}

Water Budget $\left(\mathrm{kg} \mathrm{m}^{-2}\right.$ day $\left.^{-1}\right)$

Energy Budget $\left(\mathrm{W} \mathrm{m}^{-2}\right)$
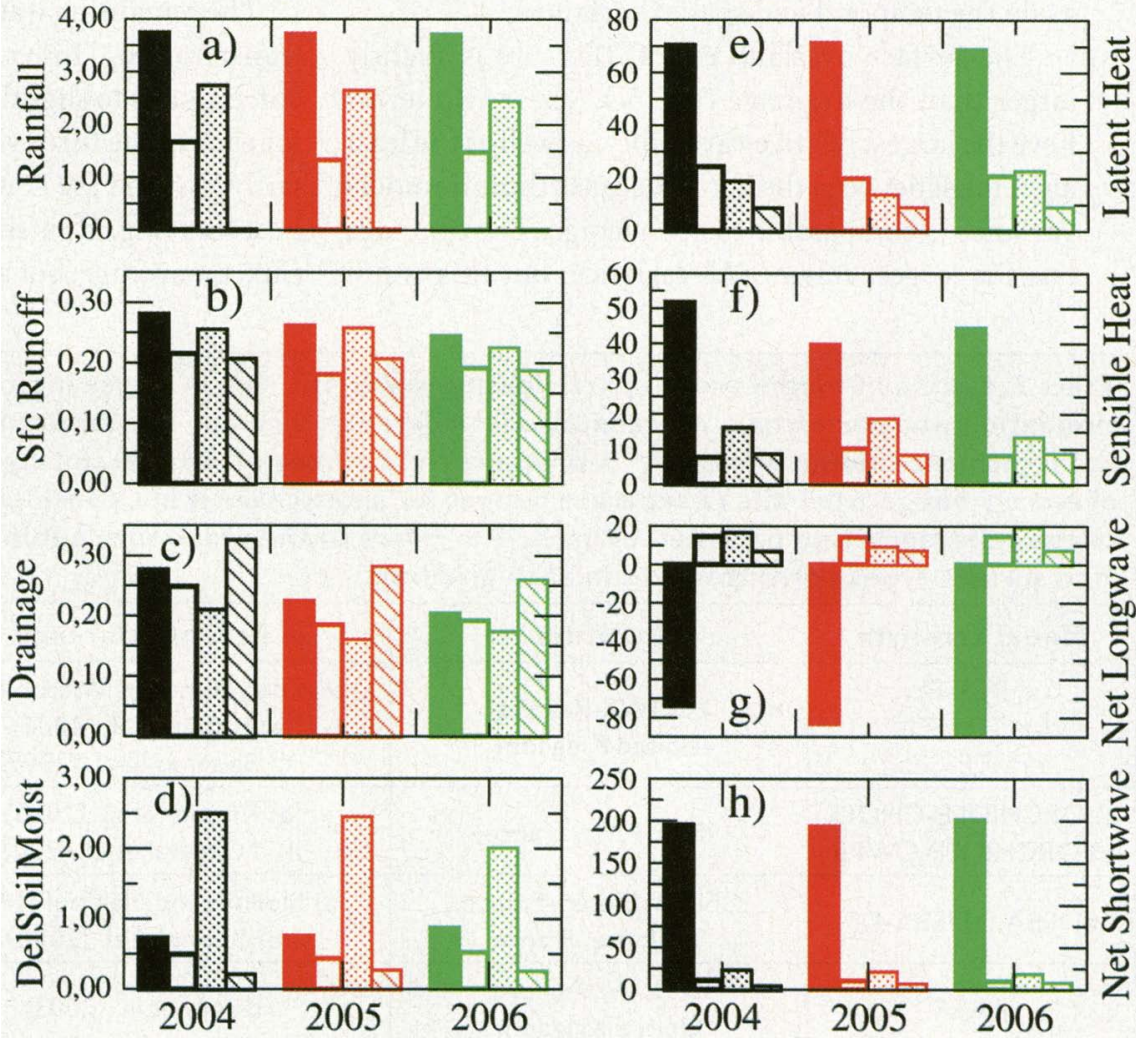

FIG. 5. A comparison of the mean (solid bars) water and energy budget components simulated by the LSMs for three years using TRMM rainfall (experiment 3). The means correspond to the average over the Sahel zone (Fig. I), the 4-month period of JJAS (using daily values), and more than nine LSMs. The spatial, temporal, and intramodel variances are represented by the whitefilled, strippled, and cross-hatched bars, respectively.

mean during JJAS for experiment 3 from 2004 to 2006 over the Sahel. These are respectively defined as

Rainfall $=$ SfcRunoff + Drainage + DelSoilMoist + Evap

SWnet + LWnet $\sim=$ Sensible Heat Flux + Latent Heat Flux, 
where DelSoilMoist represents the soil water storage change. Note that over the averaging period, the surface heat storage and the ground heat flux are much smaller than the other terms, and are negected here.

The Sahel has a prolonged dry season (lasting approximately five months), followed by a steady increase in rainfall starting in about April with a peak during late July or August. Finally, there is a more rapid decrease until about the end of October. The rainfall in 2006 lagged approximately two weeks compared to that in 2004 . The rainfall began early in 2005 , but there was a lull (and a suppression of rainfall in the southern Sahel) until mid- to late July. Then, rainfall rapidly increased northward. Despite these differences, the average rainfall from TRMM varies by just a few percent between the three years (Fig. 5a), as do the temporal and spatial variances.

The surface overland runoff (Fig. 5b) is slightly larger than the drainage (Fig. $5 \mathrm{c}$ ). These two terms have the largest relative variability, as well as the least agreement between the LSMs, because the intramodel variance is comparable to the average. The drainage has the largest intra-LSM variance, but this is not surprising, because this variable is modulated by the surface runoff, the storage dynamics, vertical transfer, and finally, the evaporative uptake (in a sense, drainage is like a residual after the other above-mentioned processes have acted).

The soil water storage change (Fig. $5 \mathrm{~d}$ ) average is comparable in magnitude to the total runoff. Of note, it has an extremely large temporal variance. This is directly related and similar in magnitude to the temporal variance of the rainfall. The average soil water content (not shown) simulated by the LSMs is quite different. This is usually the case among LSMs (e.g., Dirmeyer et al. 2006a). Nonetheless, the relative intramodel agreement of the soil water storage change among the LSMs is quite good. The soil water dynamics are simulated in a fairly consistent manner in this region.

The remaining water budget variable is the evapotranspiration. This variable is the largest sink term (it corresponds to slightly more than $60 \%$ of the rainfall for each of the three years). The relative variances are fairly low, and the LSMs generally agree. The sensible heat flux (Fig. 5f) is slightly lower than the latent heat flux, on average; but again, the relative variances are

TABLE 2. Listing of model groups participating in ALMIP. The institute indicates where the ALMIP model simulation was performed. A recent model reference is given. The structure used for ALMIP is shown in the rightmost column where "L" represents the number of vertical soil layers, "E" represents the number of energy budgets per tile (a separate budget for snow cover is not considered here), and SV corresponds to the soil-vegetation parameters used. Tile refers to the maximum number of completely independent land surface types permitted within each grid box.

\begin{tabular}{|c|c|c|c|}
\hline Model acronym & Institute & Recent reference & ALMIP structure \\
\hline $\begin{array}{l}\text { a) TESSEL, } \\
\text { b) CTESSEL, } \\
\text { c) HTESSEL }\end{array}$ & $\begin{array}{l}\text { ECMWF, Reading, } \\
\text { United Kingdom }\end{array}$ & $\begin{array}{l}\text { a) Van den Hurk and Viterbo (2003), } \\
\text { b) Lafont et al. (2006), } \\
\text { c) Balsamo et al. (2009) }\end{array}$ & 4L, 6 tiles, IE SV: ECMWF \\
\hline $\begin{array}{l}\text { a) ORCHIDEE-CHOIS, } \\
\text { b) ORCHIDEE-CWRR }\end{array}$ & IPSL, Paris, France & $\begin{array}{l}\text { a) Krinner et al. (2005), } \\
\text { b) d'Orgeval et al. (2008) }\end{array}$ & $\begin{array}{l}\text { a) } 2 \mathrm{~L} \text {, b) IIL, I3 tiles, IE SV: } \\
\text { Ecoclimap }\end{array}$ \\
\hline a) ISBA, b) ISBA-DF & $\begin{array}{l}\text { CNRM, Météo-France, } \\
\text { Toulouse, France }\end{array}$ & $\begin{array}{l}\text { a) Noilhan and Mahfouf (1996), } \\
\text { b) Boone et al. (2000) }\end{array}$ & $\begin{array}{l}\text { a) } 3 \mathrm{~L}, \text { b) } 5 \mathrm{~L}, \text { I tile, IE SV: } \\
\text { Ecoclimap }\end{array}$ \\
\hline JULES & $\begin{array}{l}\text { CEH, Wallingford, } \\
\text { United Kingdom }\end{array}$ & Essery et al. (2003) & 4L, 9 tiles, IE SV: Ecoclimap \\
\hline SETHYS & $\begin{array}{c}\text { CETP/LSCE, Vélizy, France/ } \\
\text { Gif-sur-Yvette, France }\end{array}$ & Coudert et al. (2006) & 2L, 12 tiles, 2E SV: Ecoclimap \\
\hline IBIS & $\begin{array}{l}\text { ISE-Montpellier, France; SAGE, } \\
\text { UW Madison-Madison, WI }\end{array}$ & Kucharik et al. (2000) & 6L, I tile, 8E SV: Ecoclimap \\
\hline $\mathrm{NOAH}$ & CETP/LSCE (NCEP) & $\begin{array}{c}\text { Chen and Dudhia (200I), } \\
\text { Decharme (2007) }\end{array}$ & 7L, I2 tiles, IE SV: Ecoclimap \\
\hline CLSM & UPMC, Paris, France & Koster et al. (2000) & 3L, 5 tiles, 3E SV: Ecoclimap \\
\hline MSHE & $\begin{array}{c}\text { University of Copenhagen, } \\
\text { Copenhagen, Denmark }\end{array}$ & Graham and Butts (2006) & 42L, I tile, IE SV: Ecoclimap \\
\hline SSiB & $\begin{array}{l}\text { LETG, Nantes, France; } \\
\text { UCLA, Los Angeles, CA }\end{array}$ & Xue et al. (1991) & 3L, I tile, 2E SV: SSiB \\
\hline SWAP & IWP, Moscow, Russia & Gusev et al. (2006) & 3L, I tile, IE SV: Ecoclimap \\
\hline
\end{tabular}


fairly low. This implies that for a given rainfall over this region, the various LSMs simulate the surfaceatmosphere transfer of heat and moisture fairly consistently.

The net longwave and shortwave radiation fluxes (Figs. 5g,h, respectively) have the lowest variances in the energy budget, especially the intramodel variance, as expected. The prescribed downwelling fluxes dominate the forcing input, and the vast majority of the LSMs used the prescribed surface characteristics (albedo and emissivity). The spatial and temporal net longwave variances are a bit larger than those for the shortwave radiation, and they vary more from year to year. This results because there is a significant contribution from the simulated surface temperature (which is the result of the computation of the surface energy budget).

\section{SIMULATION EVALUATION METHODOLOGY. The obvi-} ous problem, in doing simulations over western Africa (and, in fact, for many large domain area applications), is the lack of appropriate evaluation data. However, in AMMA, considerable effort has been put into addressing such issues by processing remote sensing datasets and by establishing several dense surface observational networks along a meridional transect (Fig. 1; see also Redelsperger et al. 2006). In this paper, we give examples of ALMIP LSM evaluation methods at the gridbox scale and over a largescale region.

Gridbox evaluation. Comparing local flux data with model output over a grid square is a scale problem. It is generally only useful if the grid-square surface parameters and forcing data are consistent with those observed at the local scale. There can be significant subgrid heterogeneity on the grid-square scale. This problem is being addressed in ALMIP using spatially aggregated surface flux data. We give an example for the Mali supersite square (an approximately $60 \times$ $60 \mathrm{~km}^{2}$ area; see Fig. 1), which is typical of the grid size of global-scale NWP models and relatively highresolution GCMs.

Figure 6 compares the observed upscaled surface sensible heat flux $Q h$ with the multimodel ALMIP
Observed and Simulated Sensible Heat Fluxes

Mali mesoscale domain: 2005-2007 (ALMIP Exp3)

FIG. 6. The 3-yr average (2005-07) observed $Q h$ for the three local sites are indicated by the nonfilled symbols, and the shaded green area corresponds to the spread of the spatially aggregated fluxes (representing the $60 \times 60 \mathrm{~km}^{2}$ mesoscale domain). The solid purple curves enclose a region bounded by \pm one standard deviation about the ALMIP LSM average $Q h$ averaged over 2005-07. Note that experiment 3 results are used here because they extend to 2007 . The observed flux data for this figure were taken from Timouk et al. (2009).

spread (both averaged here over 10-day periods) for a single grid box. The spread of spatially aggregated surface fluxes is computed as the range in aggregated $Q h$. The different aggregated values were computed using different weighting schemes based on the spatial coverage of the dominant vegetation type at each site, and the ranges in the soil types, the surface albedo, and the coverage of standing water using remotely sensed data (see Timouk et al. 2009 for further details).

Each of the three observation sites in Fig. 6 represents a very different land cover type: Kelma is a low-lying marsh during the wet season and ensuing months (hence, the negative $Q h$ values); Eguerit is very dry and rocky (soils quickly drain, thus $Q h$ remains relatively high all year); and Agoufou has sparse, low vegetation. This is the dominant vegetation coverage over the mesoscale area, and the ALMIP land cover for this grid box from Ecoclimap (87\% bare soil and $13 \%$ tropical grassland) is most consistent with the characteristics of this site.

ALMIP LSM average $Q h$ values are approximately $70 \mathrm{~W} \mathrm{~m}^{-2}$ just before the onset of the summer rains (prior to yearday 180 in Fig. 6). They are approximately 2 times lower during the core monsoon period (yeardays 200-260). After yearday 260, Qh rapidly increases as the rains cease. However, $Q h$ begins to 

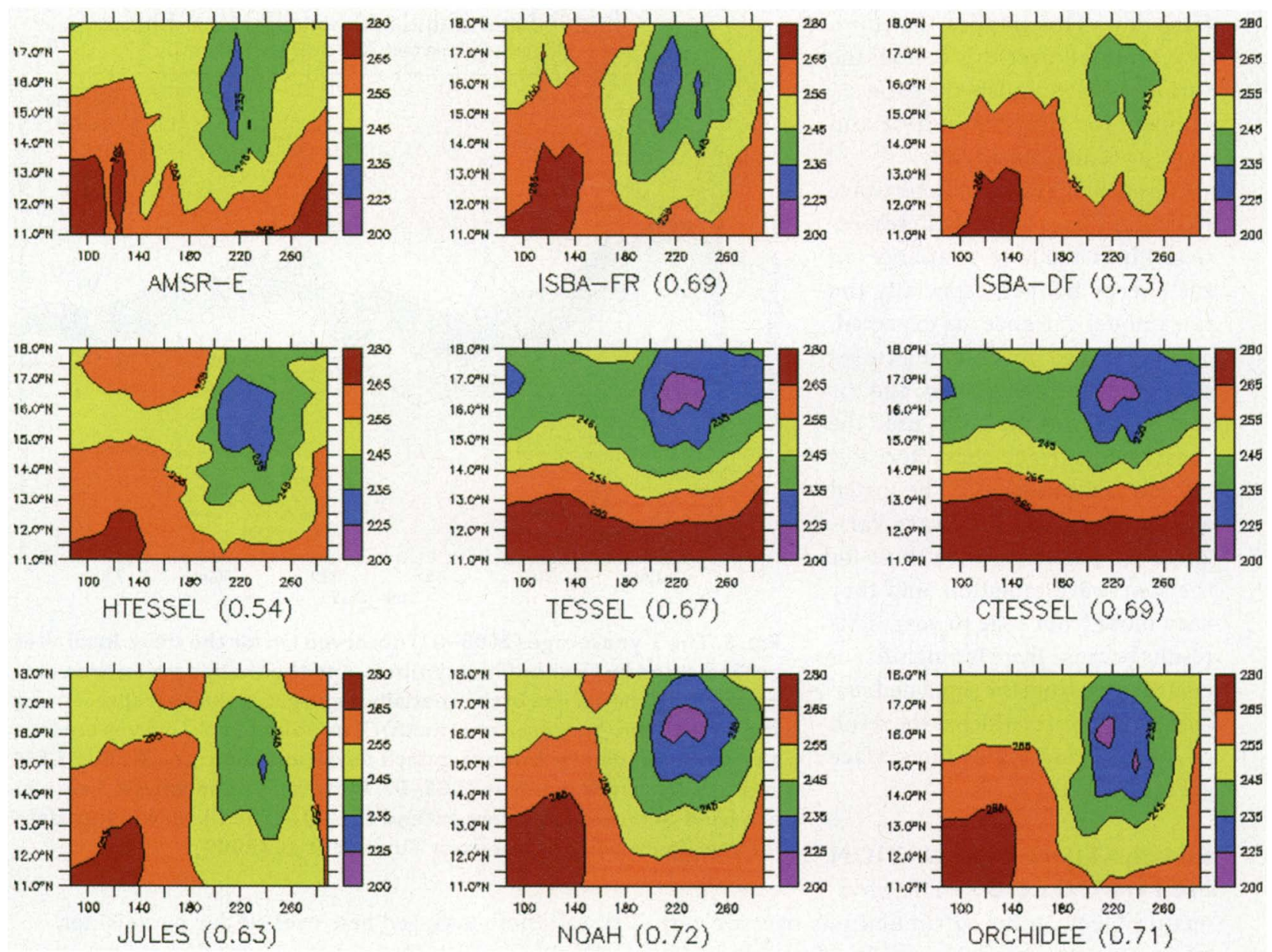

FIG. 7. (top left) The surface brightness temperature $\left(T_{B}\right)$ observed from AMSR-E is shown (top left), while the $T_{B}$ values simulated by several ALMIP models are shown in the remaining panels. The spatial correlation coefficient is indicated in parentheses. Data for this figure were taken from de Rosnay et al. (2009).

decline again after yearday 280 in response to reduced incoming radiation. The LSM average simulated $Q h$ response to the wet season and the subsequent dry down are similar to the dynamic of the observed average $Q h$. There was far less year-to-year variability (not shown in Fig. 6) than intersite variability.

Large-scale surface evaluation. Within the joint framework of the Soil Moisture and Ocean Salinity (SMOS) satellite mission and AMMA, we evaluated ALMIP soil moisture for 2006 for eight LSMs from experiment 2 (whose results had already been processed). The ALMIP Microwave Emission Model (MEM) couples ALMIP soil moisture and temperature outputs to the Community Microwave Emission Model (CMEM; de Rosnay et al. 2009). It permits a quantification of the relative impact of land surface modeling and radiative transfer modeling on the simulated brightness temperature background errors. We evaluated ALMIP MEM brightness temperatures for 2006 against Advanced Microwave Scanning Radiometer for Earth Observing System (AMSR-E) C-band data provided by the National Snow and Ice Data Center (NSIDC). This work (Fig. 7) has been a part of the effort to test different forward models for data assimilation in the ECMWF model.

For each LSM, a simple correction has been applied to the simulated brightness temperatures based on the annual mean bias. LSMs need to reproduce features such as the observed wet patch centered at yearday 210 and $15.5^{\circ} \mathrm{N}$, which can induce mesoscale circulations (Taylor et al. 2007). All of the LSMs capture this wet patch, but they either overestimate or underestimate the amplitude. However, Fig. 7 and the Taylor diagram in Fig. 8 emphasize the general good agreement between the forward approach and the AMSR-E.

In this study, CMEM has been used with the Kirdyashev vegetation opacity model (Kirdyashev et al. 1979) and the Wang and Schmugge dielectric model (Wang and Schmugge 1980) satellite data. 
Exceptions are the ECMWF LSMs using the old hydrology (TESSEL and CTESSEL), which overestimated the variance. The newer (now operational) scheme has excellent agreement (HTESSEL), although the correlation has decreased.

This analysis also indirectly evaluates the ALMIP experiment 2 precipitation forcing. The LSMs were forced by pure NWP-based forcing data (meaning no satellite or observational data were used, see experiment 1), and the CMEM results were poor compared to the AMSR-E data (not shown here). In the future, we plan to rerun these tests using experiment 3 outputs. For a more in-depth analysis of these results, see de Rosnay et al. (2009).

Large-scale subsurface evaluation. Knowledge of the land surface water storage is important for estimating vegetation growth, and it may hold a key to increasing long-range atmospheric predictability over West Africa. However, even though numerous local-scale site measurements are now available within AMMA, measurements of the land water storage are not available at the regional scale. The Gravity Recovery and Climate Experiment (GRACE) satellite mission accurately measures gravity field variations, which are inverted to retrieve terrestrial water storage variations. Various products, based on different retrieval methods, are available. Here we present results using one of the most recent methods (Lemoine et al. 2007). GRACE has already been used with success to estimate regional-scale water storage in LSM studies (e.g., Zaitchik et al. 2008).

For 2005-06, GRACE soil moisture seasonal amplitudes are larger than those simulated by the ALMIP models, although the experiment 3 results are much closer than the experiment 1 results using NWP forcing. Indeed, this is further evidence that satellitebased remote sensing offers an improvement to NWP forcing data. The experiment 3 temporal correlation for the two years is quite good (0.90). The differences in the amplitudes (the temporal variance for the mean of the ALMIP LSM is $29 \mathrm{~kg} \mathrm{~m}^{-2}$, while it is $45 \mathrm{~kg} \mathrm{~m}^{-2}$ for GRACE) can be due to a deficit in the precipitation forcing, or to an overestimation of the water storage anomalies derived from GRACE during the dry season. It is also possible that the ALMIP LSMs do not use sufficiently deep soil depths (in most LSMs, drained water is not retained in the vertical column, but rather it is assumed to be lost to the nearest river). Note that results from experiment 2 are not shown in Fig. 9, but in fact the water variation amplitude is smaller than that in experiment 3. This is consistent with the lower rainfall (used in experiment 2). A study is currently under way that shows that the satellite data reproduce the ALMIP experiment 3 LSM-modeled interannual variability over the Sahel during the study time period (2002-07). The next step is to use discharge to estimate the regional-scale evaporation.

CONCLUSIONS. There is a need to better understand land-atmosphere and hydrological processes over western Africa because of their potential feedbacks with the WAM circulation. This is being addressed through a multiscale modeling approach using an ensemble of LSMs that relies on dedicated, satellite-based forcing and land surface parameter products, and data from the AMMA observational field campaigns. The idea is to have the best estimate of surface processes for initializing and evaluating the surface component of atmospheric models, and to determine which LSM processes agree the least (in order to eventually improve the corresponding physics). The far-reaching goal of this effort is to obtain better understanding and prediction of the WAM to improve water management and agricultural practices.

Offline, multi-LSM simulations using a mix of NWP and satellite-based forcing data comprise the equivalent of a multimodel reanalysis product. This represents the best estimate of the land surface processes over large-scale regions (Dirmeyer et al. 2006a), and ALMIP has produced such an analysis for West Africa from 2004 to 2007. The use of using satellite-based forcings to correct systematic biases in NWP meteorological forcing significantly improves

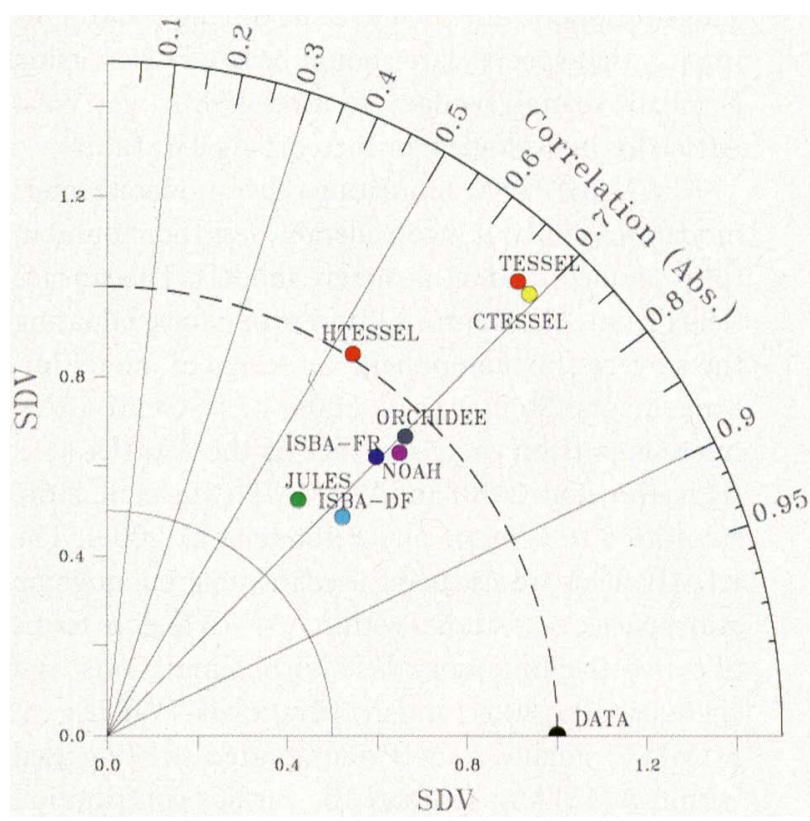

FIG. 8. Taylor diagram of the statistical evaluation of the simulated ALMIP $T_{B}$ values. Data for this figure were taken from de Rosnay et al. (2009). 


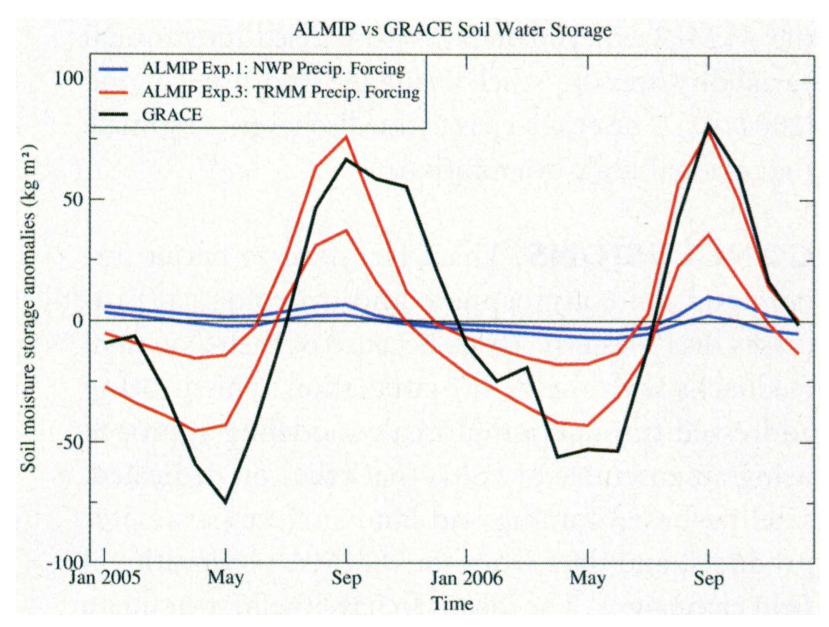

FIG. 9. Comparison of the soil moisture storage change anomaly derived from the GRACE satellite product (black curve) to two simulations by the ALMIP LSMs over the Sahel from 2005 to 2006 . The blue lines enclosed the mean plus the root-mean-square difference for results from experiment I (using NWP rainfall forcing). The red lines correspond to results from experiment 3 (using TRMM rainfall input).

LSM-simulated evapotranspiration, especially over the Sahel and areas slightly southward [which is theorized to be the zone with considerable coupling with the atmosphere; e.g., Koster et al. (2004)]. In terms of ECMWF forcing data, this corresponds to a several hundred kilometer shift in precipitation compared to satellite-based data (and 60\% less precipitation over the Sahel than in the TRMM-merged satellite-rain gauge product from 2004 to 2006 during JJAS). This implies that special care should be used when using NWP, or reanalysis data, to force LSMs over West Africa for hydrological or meteorological studies.

The ALMIP LSM simulations have moderate intermodel variability. It is considerably less than found in fully coupled land-atmosphere models. The surface fields from ALMIP are a good proxy for evaluating the surface flux components in terms of model improvements (Steiner et al. 2009) or in GCM-RCM intercomparison exercises, such as the AMMA MIP (Hourdin et al. 2010) and WAMME (Xue et al. 2010, submitted to Climate Dyn.; Boone et al. 2009). The ALMIP fields are also being used in numerous ongoing atmospheric case studies within AMMA (e.g., in terms of convective initiation, dust storm simulations, and chemical deposition) and in operational NWP (e.g., at ECMWF). Finally, ALMIP outputs are also being used within AMMA to estimate the surface contribution for atmospheric water budget studies and to estimate the production functions (evapotranspiration) for hydrological models.
There are considerable differences in terms of the partitioning of the surface (fast response: on the scale of a rainfall event) and drainage (slow response: on the scale of days up to approximately one week) runoff components. This partitioning is important because it modulates the amount of water that is evaporated, stored in lakes, transferred to rivers, or stored in the soil (which in turn impacts the partitioning of net radiation at the surface into latent and sensible heat fluxes). In addition, the intramodel variability is the largest of all of the land surface variables. These output fields have a very high degree of uncertainty. This component of the water budget is also the most sensitive to the precipitation input forcing. This aspect of LSMs must be refined if such models are to be used for regional-scale water management over West Africa, or in order for the popular soil moisture memory question to be properly addressed using coupled models (e.g., Douville et al. 2007). Increased surface runoff corresponds to reduced water recycling with the atmosphere, and it can impact the time scale and magnitude of this memory.

It is difficult to evaluate the realism of the simulated turbulent fluxes at regional scales. Indirect methods are being used for large-scale evaluation, which were all based on using remotely sensed data. A sample of such work was presented herein. The ALMIP LSMs compared favorably with aggregated surface flux data in the Sahel during the monsoon season over a 3-yr period for a given grid box. They are able to reasonably capture both the amplitude and the phase of the observed changes. At the regional scale, the simulated surface brightness temperature compared well with data from the satellite (which is a first step for assimilating such data into LSMs for operational NWP). Finally, estimates of water storage from GRACE show that the TRMM satellite-based precipitation product is more realistic than NWP-based forcing on the regional scale. This is currently the only method available to obtain reasonable estimates of the subsurface water storage over the entire West African region aside from using LSM models (in an offline mode or using some form of land data assimilation scheme).

PERSPECTIVES. ALMIP is an ongoing project, and phase 1 at the regional scale is nearing completion. However, further regional-scale simulations, experiments, and model evaluation will also be made as improved input data are made available. ALMIP phase 2 is scheduled to begin in 2009. This will focus on simulations for the three mesoscale supersites, in addition to several other local-scale sites (in Senegal, Ghana, etc.). There will be a special focus on semarid land surface process parameterizations. Indeed, they are quite 
diverse among LSMs and generally lack consideration of some fundamental processes specific to this region (reduced infiltration over dry, crusty soils, droughtresistant plant species, lateral transfer of surface runoff from bare soil to vegetated surface areas, etc.). In addition, input rainfall will be based on dense observational networks, which should improve the realism of the land surface and hydrological simulations.

Météo-France is developing a new high-resolution version of Ecoclimap over West Africa. The main drawback of the current version of Ecoclimap is that there is no vegetation interannual variability (which, in fact, is fairly typical of such datasets used currently in GCM and NWP applications). However, this variability is known to be particularly large over this region (Philippon et al. 2007). The new Ecoclimap should further improve surface flux estimates. This is important from a modeling standpoint because the observed vegetation interannual variability is correlated with the precipitation over this region, notably, for the Sahel (Philippon et al. 2005). It will also be available for atmospheric model studies.

LSMs, which are able to simulate the life cycle of the vegetation, are increasingly used in GCMs. They will theoretically enable a more realistic feedback between the vegetation and potential increases in greenhouse gases in climate scenario studies. There will be a coordinated effort in ALMIP phase 2 to intercompare such LSMs on the mesoscale, which will be a first. ALMIP phase 1 focused on making a robust multimodel representation of surface processes. ALMIP phase 2 will also focus on improving the representation of such processes (for atmospheric and hydrological models). ALMIP phase 2 will be open to the general scientific community. Interested parties will be encouraged to participate.

ACKNOWLEDGMENTS. The authors would like to acknowledge the support of J.-P. Lafore at CNRM and the data providers, notably R. Lacaze, B. Geiger, D. Carrer, and J.-L. Roujean, who have offered considerable assistance with respect to using the LSA SAF downwelling radiative flux products. A. Marsouin provided guidance on the OSI SAF radiation product. We wish to extend our gratitude to the POSTEL Service Centre (http://postel.mediasfrance. org) at MEDIAS-France for customizing and providing the LSA SAF products, and to the people working on the AMMA-SAT database (http://ammasat.ipsl.polytechnique. fr) who have generated the EPSAT precipitation product developed by the Precip-AMMA group at IPSL/LMD (notably, K. Ramage). Thanks go to R. Meynadier who processed the TRMM data. Based on a French initiative, AMMA has been established by an international group and is currently funded by a large number of agencies, especially from France, the United Kingdom, and Africa. It has been the beneficiary of a major financial contribution from the European Community's Sixth Framework Research Programme. Detailed information on scientific coordination and funding is available on the AMMA international Web site (www.amma-eu.org/). Finally, we would like to acknowledge the efforts of three reviewers and the editor in improving this manuscript.

APPENDIX A: INPUT DATA. Additional details related to the input forcing data are presented herein.

Soil and vegetation model parameters. The Ecoclimap database (Masson et al. 2003) provides land surface parameters (albedo, vegetation cover fraction, surface roughness, leaf area index, soil texture, etc.) over the entire globe at a maximum spatial resolution of $1 \mathrm{~km}$. It is intended for use by LSMs that are coupled to GCMs, numerical weather prediction (NWP) models, mesoscale meteorological research models, or hydrological models. The vegetation phenology for a single representative annual cycle, at a 10 -day time step, is derived from the International Geosphere-Biosphere Programme (IGBP) 1-km Advanced Very High Resolution Radiometer (AVHRR) monthly normalized difference vegetation index (NDVI).

Atmospheric forcing. The forcing variables have been interpolated to a $0.5^{\circ}$ cylindrical, equidistant projection at a 3 -h time step. There is a well-known spindown problem in terms of the simulated precipitation for the ECMWF model. The ALMIP forcing consists of a series of 36-h forecasts at 1200 UTC every $24 \mathrm{~h}$, and the first $12 \mathrm{~h}$ are not used. In experiment 2, EPSAT rainfall replaced NWP data for the monsoon months. When either satellite-based radiative flux or precipitation data were missing, they were replaced by NWP data. In experiment 3, TRMM rainfall was used for all years (including spinup), and SAF fluxes were used from 2004 onward (refer to Table 1).

APPENDIX B: MODEL SETUP. This section describes the LSM configurations for ALMIP. Please refer to Table B1 for model references and scheme details referred to herein.

LSM initialization and output diagnostics. All of the models performed spinup for 2002 because initial conditions for each of the LSMs were not available. A single pass through 2003 was done as an adjustment year. The values of the prognostic variables at the end 
of 2003 were then used as initial values for experiments 1 and 2. Nine of the 11 models (except for IBIS and MSHE) performed experiment 3. Model results were reported for all years, however, analysis focuses on 2004-07 because satellite-based radiative flux data and the EPSAT product were available (2004-06). This period also encompasses the special observation perdio in AMMA. A number of water and energy budget variables and diagnostics were reported at a 3-h time step. The output variables and conventions are essentially the same as those outlined in Dirmeyer et al. (2006a): the outputs consist in energy budget diagnostics (such as surface heat, mass, momentum, and radiative fluxes), water budget components (runoff, evapotranspiration, and soil water storage changes), and prognostic variables (soil temperature and moisture for ALMIP; see www.cnrm.meteo.fr/ amma-moana/amma_surf/almip/index.html for a complete listing of LSM outputs).

LSM options. Two models did simulations using two different options. ISBA used the force-restore and the multilayer diffusion (DIF) soil options ORCHIDEE replaced its two-layer soil approach (CHOIS) by an explicit, multilayer model. HTESSEL uses the newly implemented hydrological updates (TESSEL was operational until recently), and CTESSEL contains a new photosynthesis option. All of the LSMs used the same computational grid and atmospheric forcing.

Several of the models used multiple tile options for these experiments because it is their default setting. This essentially amounts to an explicit treatment of each surface land cover type and aggregating the fluxes using weights based on spatial coverage within each grid box (in order to theoretically better represent the nonlinearity of the surface processes). Most of the LSMs use either a single composite or a doubleenergy budget representation (explicit treatment of canopy and soil). However, a few schemes have unique treatments. CLSM computes three energy budgets based on soil wetness, while ORCHIDEE computes evaporation for different surface types overlying the same soil. IBIS also uses a similar approach with four distinct plant functional types, and it has the most detailed representation of the canopy containing multiple energy budgets. Finally, the MSHE model was designed for hydrological applications, and it uses a very detailed treatment of vertical, subsurface fluxes of mass and energy (utilizing 42 layers).

LSM ensemble mean. Multiple simulations from the same model were first averaged to obtain a single representative result for a given model (e.g., ISBA and ISBA-DIF results were averaged to obtain a single ISBA representative result). This was done because the differences between multiple simulations by a single model were generally far less than the intra-LSM differences: we did not want to bias the ensemble average by weighting one model more than another.

\section{REFERENCES}

Balsamo, G., P. Viterbo, A. Beljaars, B. van den Hurk, M. Hirsch, A. Betts, and K. Scipal, 2009: A revised hydrology for the ECMWF model: Verification from field site to terrestrial water storage and impact in the Integrated Forecast System. J. Hydrometeor., 10, 623-643.

Boone, A., V. Masson, T. Meyers, and J. Noilhan, 2000: The influence of the inclusion of soil freezing on simulations by a soil-vegetation-atmosphere transfer scheme. J. Appl. Meteor., 39, 1544-1569.

—, and Coauthors, 2004: The Rhone-Aggregation Land Surface Scheme Intercomparison Project: An overview. J. Climate, 17, 187-208.

_- Y. Xue, I. Poccard-Leclerq, J. Feng, and P. deRosnay, 2009: Evaluation of the WAMME model surface fluxes using results from the AMMA land-surface model intercomparison project. Climate Dyn., in press, doi:10.1007/s00382-009-0653-1.

Charney, J. G., 1975: Dynamics of desert and drought in the Sahel. Quart. J. Roy. Meteor. Soc., 101, 193-202.

—, P. H. Stone, and W. J. Quirk, 1975: Drought in the Sahara: A biogeophysical feedback mechanism. Science, 187, 434-435.

Chen, F., and J. Dudhia, 2001: Coupling an advanced land surface-hydrology model with the Penn State-NCAR MM5 modeling system. Part I: Model implementation and sensitivity. Mon. Wea. Rev., 129, 569-585.

Chopin, F., J. Berges, M. Desbois, I. Jobard, and T. Lebel, 2004: Multi-scale precipitation retrieval and validation in African monsoon systems. Second Int. TRMM Science Conf., Nara, Japan, TRMM, 40 pp.

Cook, K. H., and E. K. Vizy, 2006: Coupled model simulations of the West African monsoon system: Twentieth and twenty-first-century simulations. J. Climate, 19, 3681-3703.

Coudert, B., C. Ottlé, B. Boudevillain, P. Guillevic, and J. Demarty, 2006: Contribution of thermal infrared remote sensing data in multiobjective calibration of a dual source SVAT model. J. Hydrometeor., 7, 404-420.

Cunnington, W. M., and P. R. Rowntree, 1986: Simulations of the Saharan atmosphere dependence on moisture and albedo. Quart. J. Roy. Meteor. Soc., 112, 971-999. 
Decharme, B., 2007: Influence of runoff parameterization on continental hydrology: Comparison between the Noah and the ISBA land surface models. J. Geophys. Res., 112, D19108, doi:10.1029/2007JD008463.

de Rosnay, P., and Coauthors, 2009: AMMA Land Surface Model Intercomparison Experiment coupled to the Community Microwave Emission Model: ALMIP-MEM. J. Geophys. Res., 114, D05108, doi:10.1029/2008JD010724.

Dirmeyer, P. A., X. Gao, M. Zhao, Z. Guo, T. Oki, and N. Hanasaki, 2006a: GSWP-2: Multimodel analysis and implications for our perception of the land surface. Bull. Amer. Meteor. Soc., 87, 1381-1397.

— , R. D. Koster, and Z. Guo, 2006b: Do global models properly represent the feedback between land and atmosphere? J. Hydrometeor., 7, 1177-1198.

d'Orgeval, T., J. Polcher, and P. de Rosnay, 2008: Sensitivity of the West African hydrological cycle in ORCHIDEE to infiltration processes. Hydrol. Earth Syst. Sci. Discuss., 5, 2251-2292.

Douville, H., F. Chauvin, and H. Broqua, 2001: Influence of soil moisture on the Asian and African monsoons. Part I: Mean monsoon and daily precipitation. $J$. Climate, 14, 2381-2403.

—, S. Conil. S. Tyteca, and A. Voldoire, 2007: Soil moisture memory and West African monsoon predictability: Artefact or reality? Climate Dyn., 28, 723-742.

Eltahir, E. A. B., and C. Gong, 1996: Dynamics of wet and dry years in West Africa. J. Climate, 9, 1030-1042.

Essery, R. L. H., M. Best, R. Betts, P. Cox, and C. M. Taylor, 2003: Explicit representation of subgrid heterogeneity in a GCM land surface scheme. J. Hydrometeor., 4, 530-543.

Folland, C. K., T. N. Palmer, and D. E. Parker, 1986: Sahel rainfall and worldwide sea temperature 1901-1985. Nature, 320, 602-607.

Fontaine, B., and S. Janicot, 1996: Sea surface temperature fields associated with West African rainfall anomaly types. J. Climate, 9, 2935-2940.

Gao, X., and P. A. Dirmeyer, 2006: A multimodel analysis, validation, and transferability study of global soil wetness products. J. Hydrometeor, 7, 1218-1236.

Geiger, B., C. Meurey, D. Lajas, L. Franchistéguy, D. Carrer, and J.-L. Roujean, 2008: Near real-time provision of downwelling shortwave radiation estimates derived from satellite observations. Meteor. Appl., 15, 411-420.

Graham, D. N., and M. B. Butts, 2006: Flexible integrated watershed modeling with MIKE SHE. Watershed Models, V. P. Singh and D. K. Frevert, Eds., Taylor and Francis Group, 245-272.
Gusev, E. M., O. N. Nasonova, and E. E. Kovalev, 2006: Modeling the components of heat and water balance for the land surface of the globe. Water Resour., 33, 616-627.

Henderson-Sellers, A., A. J. Pitman, P. K. Love, P. Irannejad, and T. Chen, 1995: The Project for Intercomparison of Land-Surface Parameterization Schemes (PILPS): Phases 2 and 3. Bull. Amer. Meteor. Soc., 76, 489-503.

Hourdin, F., and Coauthors, 2010: AMMA Model Intercomparison Project. Bull. Amer. Meteor. Soc., in press.

Huffman, G. J., and Coauthors, 2007: The TRMM Multisatellite Precipitation Analysis (TMPA): Quasiglobal, multiyear, combined-sensor precipitation estimates at fine scales. J. Hydrometeor., 8, 38-55.

Kirdyashev, K., A. Chukhlantsev, and A. Shutko, 1979: Microwave radiation of the earth's surface in the presence of vegetation cover. Radio Eng. Electron., 24, 256-264.

Koster, R. D., M. J. Suarez, A. Ducharne, P. Kumar, and M. Stieglitz, 2000: A catchment based approach to modeling land surface processes in a GCM-Part 1: Model structure. J. Geophys. Res., 105, 24 809-24822.

_, P. A. Dirmeyer, A. N. Hahmann, R. Ijpelaar, L. Tyahla, P. Cox, and M. J. Suarez, 2002: Comparing the degree of land-atmosphere interaction in four atmospheric general circulation models. J. Hydrometeor., 3, 363-375.

_- and Coauthors, 2004: Regions of strong coupling between soil moisture and precipitation. Science, 305, 1138-1140.

Krinner, G., and Coauthors, 2005: A dynamic global vegetation model for studies of the coupled atmosphere-biosphere system. Global Biogeochem. Cycles, 19, GB1015, doi:10.1029/2003GB002199.

Kucharik, C. J., and Coauthors, 2000: Testing the performance of a dynamic global ecosystem model: Water balance, carbon balance and vegetation structure. Global Biogeochem. Cycles, 14, 795-825.

Lafont, S., A. Beljaars, M. Voogt, L. Jarlan, P. Viterbo, B. van den Hurk, and J.-C. Calvet, 2006: Comparison of C-TESSEL CO fluxes with TransCom $\mathrm{CO}_{2}$ fluxes. Proc. Second Recent Advances in Quantitative Remote Sensing II, Torrent, Spain, University of Valencia, $474-477$.

Laval, K., and L. Picon, 1986: Effect of a change of the surface albedo of the Sahel on climate. J. Atmos. Sci., 43, 2418-2429.

Le Barbé, L., T. Lebel, and D. Tapsoba, 2002: Rainfall variability in West Africa during the years 1950-90. J. Climate, 15, 187-202. 
Lemoine, J.-M., S. Bruinsma, S. Loyer, R. Biancale, J.-C. Marty, F. Perosanz, and G. Balmino, 2007: Temporal gravity field models inferred from GRACE data. Adv. Space Res., 39, 1620-1629, doi:10.1016/j. asr.2007.03.062.

Li, W., Y. Xue, and I. Poccard, 2007: Numerical investigation of the impact of vegetation indices on the variability of West African summer monsoon. J. Meteor. Soc. Japan, 85A, 363-383.

Masson, V., J.-L. Champeaux, F. Chauvin, C. Meriguet, and R. Lacaze, 2003: A global database of land surface parameters at $1-\mathrm{km}$ resolution in meteorological and climate models. J. Climate, 16, 1261-1282.

Mitchell, K. E., and Coauthors, 2004: The multi-institution North American Land Data Assimilation System (NLDAS): Utilizing multiple GCIP products and partners in a continental distributed hydrological modeling system. J. Geophys. Res., 109, D07590, doi:10.1029/2003JD003823.

Nicholson, S. E., 1980: The nature of rainfall fluctuations in subtropical West Africa. Mon. Wea. Rev., 108, $473-487$.

- 2000: Land surface processes and Sahel climate. Rev. Geophys., 38, 117-139.

— , and Coauthors, 2003: Validation of TRMM and other rainfall estimates with a high-density gauge dataset for West Africa. Part II: Validation of TRMM rainfall products. J. Appl. Meteor., 42, $1355-1368$.

Noilhan, J., and J.-F. Mahfouf, 1996: The ISBA land surface parameterization scheme. Global Planet. Change, 13, 145-159.

Nuret, M., J.-P. Lafore, N. Asencio, H. Bénichou, O. Bock, F. Favot, T. Montmerle, and Y. Seity, 2007: Evaluation of METEO-FRANCE NWP models during AMMA 2006-SOP. [Available online at www.cnrm.meteo.fr/ aladin/newsletters/news32/news32.pdf.]

Philippon, N., E. Mougin, L. Jarlan, and P.-L. Frison, 2005: Analysis of the linkages between rainfall and land surface conditions in the West African monsoon through CMAP, ERS-WSC, and NOAAAVHRR data. J. Geophys. Res., 110, D24115, doi:10.1029/2005JD006394.

—, L. Jarlan, N. Martiny, P. Camberlin, and E. Mougin, 2007: Characterization of the interannual and intraseasonal variability of West African vegetation between 1982 and 2002 by means of NOAA AVHRR NDVI data. J. Climate, 20, 1202-1218.

Redelsperger, J.-L., C. D. Thorncroft, A. Diedhiou, T. Lebel, D. J. Parker, and J. Polcher, 2006: African Monsoon Multidisciplinary Analysis: An international research project and field campaign. Bull. Amer. Meteor. Soc., 87, 1739-1746.
Rodell, M., and Coauthors, 2004: The global land data assimilation system. Bull. Amer. Meteor. Soc., 85, 381-394.

Steiner, A., J. Pal, S. Rauscher, J. Bell, N. Diffenbaugh, A. Boone, L. Sloan, and F. Giorgi, 2009: Land surface coupling in regional climate simulations of the West African monsoon. Climate Dyn., 33, 869-892.

Sud, Y. C., and M. Fennessy, 1982: A study of the influence of surface albedo on July circulation in semi-arid regions using the GLAS GCM. J. Climatol., 2, 105-125.

Taylor, C. M., D. J. Parker, and P. Harris, 2007: An observational case study of mesoscale atmospheric circulations induced by soil moisture. Geophys. Res. Lett., 34, L15801, doi:10.1029/2007GL030572.

Timouk, F., and Coauthors, 2009: Response of sensible heat flux to water regime and vegetation development in a central Sahelian landscape. J. Hydrol., 375, 178-189.

Tulet, P., M. Mallet, V. Pont, J. Pelon, and A. Boone, 2008: The 7-13 March dust storm over West Africa: Generation, transport, and vertical stratification. J. Geophys. Res., 113, D00C08, doi:10.1029/2008JD009871.

Van den Hurk, B., and P. Viterbo, 2003: The Torne-Kalix PILPS 2(e) experiment as a test bed for modifications to the ECMWF land surface scheme. Global Planet. Change, 38, 165-173.

Walker, J., and P. R. Rowntree, 1977: The effect of soil moisture on circulation and rainfall in a tropical model. Quart. J. Roy. Meteor. Soc., 103, 29-46.

Wang, J. R., and T. Schmugge, 1980: An empirical model for the complex dielectric permittivity of soils as a function of water content. IEEE Trans. Geosci. Remote Sens., 18, 288-295.

Wood, E. F., and Coauthors, 1998: The Project for Intercomparison of Land-Surface Parameterization Schemes (PILPS) Phase-2c Red-Arkansas River Basin experiment: 3. Experiment description and summary intercomparisons. Global Planet. Change, 19, 115-139.

Xue, Y., and J. Shukla, 1996: The influence of land surface properties on Sahel climate. Part II: Afforestation. J. Climate, 9, 3260-3275.

— , P. J. Sellers, J. L. Kinter III, and J. Shukla, 1991: A simplified biosphere model for global climate studies. J. Climate, 4, 345-364.

—, and Coauthors, 2004: The Sahelian climate. Vegetation, Water, Humans, and the Climate: A New Perspective on an Interactive System, P. Kabat et al., Eds., Springer Verlag, 59-78.

Zaitchik, B. F., M. Rodell, and R. H. Reichle, 2008: Assimilation of GRACE terrestrial water storage data into a land surface model: Results for the Mississippi River basin. J. Hydrometeor., 9, 535-548. 